\title{
The Optimization of Radiation Protection in the Design of the High Temperature Reactor-Pebble-Bed Module
}

\author{
Sida Sun, Hong Li, and Sheng Fang \\ Key Laboratory of Advanced Reactor Engineering and Safety of the Ministry of Education, Collaborative Innovation Center of Advanced \\ Nuclear Energy Technology, Institute of Nuclear and New Energy Technology, Tsinghua University, Beijing 100084, China
}

Correspondence should be addressed to Sheng Fang; fangsheng@tsinghua.edu.cn

Received 29 December 2016; Revised 20 April 2017; Accepted 16 May 2017; Published 31 July 2017

Academic Editor: Arkady Serikov

Copyright (C) 2017 Sida Sun et al. This is an open access article distributed under the Creative Commons Attribution License, which permits unrestricted use, distribution, and reproduction in any medium, provided the original work is properly cited.

The optimization of radiation protection is an important task in both the design and operation of a nuclear power plant. Although this topic has been considerably investigated for pressurized water reactors, there are very few public reports on it for pebble-bed reactors. This paper proposes a routine that jointly optimizes the system design and radiation protection of High Temperature Reactor-Pebble-Bed Module (HTR-PM) towards the As Low As Reasonably Achievable (ALARA) principle. A systematic framework is also established for the optimization of radiation protection for pebble-bed reactors. Typical calculations for the radiation protection of radioactivity-related systems are presented to quantitatively evaluate the efficiency of the optimization routine, which achieve $23.3 \% \sim 90.6 \%$ reduction of either dose rate or shielding or both of them. The annual collective doses of different systems are reduced through iterative optimization of the dose rates, designs, maintenance procedures, and work durations and compared against the previous estimates. The comparison demonstrates that the annual collective dose of HTR-PM is reduced from $0.490 \mathrm{man}$-Sv/a before optimization to $0.445 \mathrm{man}-\mathrm{Sv} / \mathrm{a}$ after optimization, which complies with the requirements of the Chinese regulatory guide and proves the effectiveness of the proposed routine and framework.

\section{Introduction}

Optimization is one of the three basic principles of radiation protection recommended by the International Commission on Radiological Protection (ICRP). Since its first formal introduction in ICRP publication 26 [1], the concept of optimization of radiation protection was continuously improved and interpreted in a series of successive ICRP publications [15]. A widely used interpretation is as follows: the likelihood of incurring exposures, the number of people exposed, and the magnitude of their individual doses should be kept As Low As Reasonably Achievable (ALARA), taking into account economic and societal factors [5]. In some contexts, the optimization of radiation protection is also known as the ALARA principle.

With respect to a nuclear power plant, there are continuous efforts in the optimization of radiation protection for both design and operation. For those power plants in operation, the radiation dose management has been successively improved following the principle of optimization and has achieved significant dose reduction in the past decades [611]. For recently developed Generation III nuclear reactors, the optimization of radiation protection has been integrated deeply into the design. The European Pressurized Water Reactor (EPR) has established the ALARA principle as one of the main objectives in the design and made a large effort to reduce both individual and collective dose to an acceptable level [12]. Another typical Generation III nuclear reactor, AP1000, takes the advantages of both operating plant experience and advanced techniques to reduce maintenance duration and doses, so as to achieve the optimization of radiation protection [13].

As one of the potential candidates for the fourthgeneration nuclear reactors, the gas-cooled pebble-bed reactor also emphasizes the optimization of radiation protection. The pioneer $15 \mathrm{MWe}$ AVR experimental high temperature reactor has achieved an average collective dose between 0.5 and $0.6 \mathrm{~Sv}$ per year during its 21 years of successful operation [14], which is considerably low. The $300 \mathrm{MWe}$ thorium high temperature reactor (THTR-300) has continued to optimize its radiation protection during both operation and decommissioning [15]. For the latest $200 \mathrm{MWe}$ High Temperature Reactor-Pebble-bed Module (HTR-PM) 


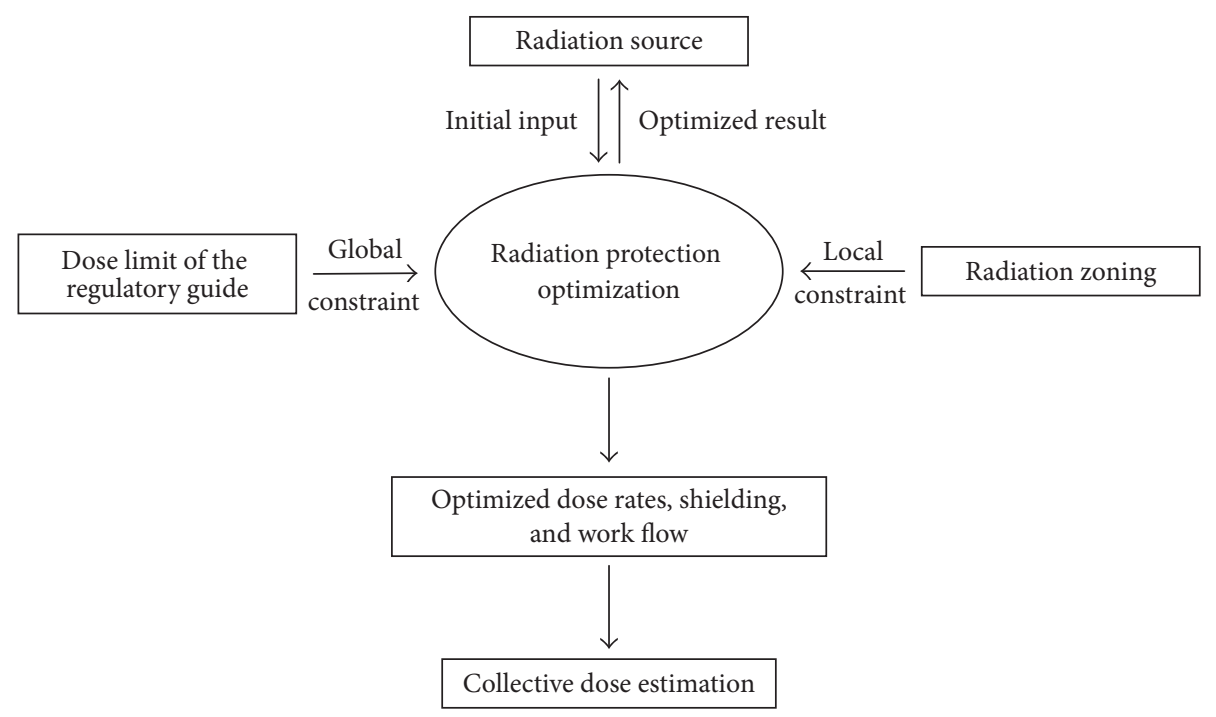

FIGURE 1: Framework of the radiation protection optimization in the HTR-PM design.

demonstration power plant, the optimization of radiation protection is not only an important goal in design [16], but also a licensing requirement demanded by the national nuclear safety administration of China.

However, compared with abundant experiences and reports on the radiation protection optimization of pressurized water reactors (PWR), there are only few reports on that of pebble-bed reactors, and even fewer on a systematic optimization of radiation protection. Given the potential deployment of pebble-bed reactors in China and other places around the world, it is necessary to build up a tailored guideline of the radiation protection optimization for industrial pebble-bed reactors. HTR-PM, which is currently under construction, provides an opportunity for this purpose.

In this study, a framework of the radiation protection optimization is proposed for HTR-PM in the design stage. In this framework, the radiation source is analyzed and a routine is formed for the joint optimization of the system design and the radiation protection of HTR-PM. The application of this routine in the HTR-PM design provides optimized dose rates, radiation protection design, and work flow of each system. Based on this optimization, the annual collective dose of HTR-PM is estimated for every radioactivityrelated work and compared with the previous estimate before optimization. The presented framework may provide useful information and experiences for the optimization of radiation protection for future pebble-bed reactors.

\section{Framework of the Radiation Protection Optimization in the HTR-PM Design}

The radiation protection optimization is a comprehensive process that involves multiple aspects of the HTR-PM design. As shown in Figure 1, the dose limit demanded by the regulatory guide is the global constraint of the optimization, while the radiation zoning serves as a local constraint for specific radiation protection tasks. The radiation source is the initial input for the first iteration of the optimization. As the iteration continues, the system design is gradually refined and the radiation source changes accordingly. At each iteration, the dose rates of the refined design and updated source term are computed and checked with the dose limit of the regulatory guide and the radiation zoning requirement. When the above two criteria are met, a series of radiation protection schemes are provided as candidates for the final design. These schemes are discussed with the designers of the involved systems and further optimized to practical issues such as the space layout of different equipment, the support of shielding structures, the accessibility of maintenance, and the cost. This iteration continues until an optimal solution that both the designers of systems and radiation protection agree on has been found.

\section{Dose Limit of the Regulatory Guide and Radiation Zoning}

3.1. Dose Limit of the Regulatory Guide. According to the HAD102/12 regulatory guide in China [17], the individual dose limit for a nuclear power plant is $20 \mathrm{mSv} / \mathrm{a}$ (five-year average) and the individual dose constraint is $15 \mathrm{mSv} / \mathrm{a}$. To be compliant with this, the individual dose limit for HTR$\mathrm{PM}$ is set to $15 \mathrm{mSv} / \mathrm{a}$, and the collective dose limit is set to $0.5 \mathrm{man}-\mathrm{Sv} / \mathrm{a}$. These two limits are global constraints for the radiation protection optimization, because they affect all radioactivity-related systems in HTR-PM and affect all aspects of the radiation protection. They provide criteria for the overall evaluation of the whole radiation protection efficiency of HTR-PM.

3.2. Radiation Zoning. Radiation zoning of HTR-PM is determined based on the possible distribution of radiation sources, the accessible requirement, and the operation and maintenance activities in certain areas. The classification of radiation 
TABLE 1: Classification of radiation zones for the HTR-PM's operation.

\begin{tabular}{|c|c|c|c|c|}
\hline Number & Name & $\begin{array}{c}\text { Dose rate } \\
(\mathrm{mSv} / \mathrm{h})\end{array}$ & $\begin{array}{c}\text { Airborne } \\
\text { radioactivity } \\
\text { concentration }\end{array}$ & Residence characteristics \\
\hline I & Supervised area & $0.0005<d \leq 0.0025$ & negligible & $40 \mathrm{~h}$ per week \\
\hline II & Conventional work area & $0.0025<d \leq 0.0075$ & $\leq 0.1 \mathrm{DAC}^{*}$ & Less than $40 \mathrm{~h}$ per week \\
\hline III & Intermittent work area & $0.0075<d \leq 0.03$ & $\leq 1 \mathrm{DAC}$ & $\begin{array}{l}\text { Usually less than } 10 \mathrm{~h} \text { per } \\
\text { week, which accordingly } \\
\text { determines the dose rate } \\
\text { upper limit }\end{array}$ \\
\hline IV & Limited work area & $0.03<d \leq 3$ & $\leq 10 \mathrm{DAC}$ & $\begin{array}{l}\text { Determined by the staff in } \\
\text { charge of radiation } \\
\text { protection }\end{array}$ \\
\hline V & Chartered work area & $d>3$ & - & Temporarily chartered \\
\hline
\end{tabular}

${ }^{*}$ Airborne radioactivity concentration is represented by derived air concentration (DAC).

TABLE 2: Level of radioactive pollution control $\left(\mathrm{Bq} / \mathrm{cm}^{2}\right)$.

\begin{tabular}{lccc}
\hline Surface type & $\begin{array}{c}\alpha \text { radioactive material } \\
\text { Extremely toxic }\end{array}$ & Others & $\beta$ radioactive material \\
\hline $\begin{array}{l}\text { Workbench, equipment, wall, and floor } \\
\quad \text { Controlled area }\end{array}$ & 4 & 40 & 40 \\
$\quad \begin{array}{l}\text { Supervised area } \\
\text { Work clothes, gloves, and work shoes }\end{array}$ & 0.4 & 4 & 4 \\
$\quad \begin{array}{l}\text { Controlled area } \\
\quad \text { Supervised area }\end{array}$ & 0.4 & 0.4 \\
Hand, skin, underwear, and work socks & 0.04 & 0.04 & 4 \\
\hline
\end{tabular}

zones for HTR-PM in power operation stage is presented in Table 1. A controlled area is designated in which specific measures for protection and safety are or could be required for (a) controlling exposures or preventing the spread of contamination in normal operation and (b) preventing or limiting the likelihood and magnitude of exposures in anticipated operational occurrences and accident conditions. An area is designated as a supervised area, on condition that specific measures for protection and safety are not normally needed [18]. But occupational exposure conditions are still kept under review for a supervised area. The controlled area is further classified into four areas: the green, the yellow, the orange, and the red area. Each of these areas is physically separated from others by concrete walls.

Since the radiation sources at some areas may change in the outage of HTR-PM, the radiation zoning of these areas is slightly different from that in plant operation. However, the classification criteria for outage are still the same ones listed in Table 1.

Besides the radiation level, the surface contamination level is also taken into consideration. The corresponding classification is provided in Table 2. Compared to the dose limit, the radiation zoning is more specific and operable for a single radiation protection task.

\section{Radiation Source}

4.1. Fission Product. According to the calculation of the reactor core inventory at equilibrium, the orders of magnitude of noble gases ( $\mathrm{Kr}$ and $\mathrm{Xe}$ ) and iodine are both $10^{16}$ Bq per MW of HTR-PM, while that of the primary metal fission products $\left({ }^{89} \mathrm{Sr},{ }^{90} \mathrm{Sr},{ }^{134} \mathrm{Cs},{ }^{137} \mathrm{Cs}\right.$, and $\left.{ }^{110 \mathrm{~m}} \mathrm{Ag}\right)$ is $10^{15} \mathrm{~Bq}$ per $\mathrm{MW}$ of HTR-PM. The majority of these fission products are retained inside the coated particles in the spherical fuel elements of HTR-PM.

Because HTR-PM uses an online refueling strategy, the irradiated spherical fuel elements keep cycling between the reactor pressure vessel (RPV) and the pipes of HTR-PM's fuel handling system which are outside the reactor cavity. Because the irradiated fuel elements carry fission products, they can temporarily increase local radiation level along their path. Thus, these mobile fuel elements are dynamic sources in a spatiotemporal transient state, which is a unique feature of HTR-PM.

When the reactor is shut down, the fuel elements in RPV and the pipes of HTR-PM's fuel handling system will be discharged, except for a few shielded devices. Thus, for the reactor cavity and the rooms near the fuel transportation pipes, the radiation level will be significantly reduced so that these rooms can be accessible for maintenance.

Another carrier of fission products is the graphite dust that is mainly produced by the abrasion between fuel elements in the reactor core or between fuel elements and the fuel transportation pipes. Its radioactivity primarily results from a very limited leakage of fission products from defective/failed coated particles in the fuel elements. Among these fission products, the gaseous radionuclides can be removed 
by the helium purification system. The solid radionuclides may be adsorbed on the fuel element surfaces by the graphite matrix. HTR-PM uses a purge system to remove such graphite dust, which is collected in shielded containers.

4.2. Activation Product. The activation products can come from the impurities in the structural material, helium coolant, and graphite matrix of fuel elements. For components in the reactor cavity, the activation level can be high due to the strong neutron flux. However, the radiation contributed by the activation products is still much lower than that of the reactor core during power operation. But in the maintenance stage, the reactor is shut down and the radiation from the reactor core drastically decreases. The $\gamma$ rays from the activation products become the primary radiation sources for the maintenance work. The activation products in the primary coolant after 40-year lifetime of HTR-PM include noble gases ( $\mathrm{Kr}$ and $\mathrm{Xe}$ ), iodine, metals with long half-lives $\left({ }^{89} \mathrm{Sr},{ }^{90} \mathrm{Sr},{ }^{134} \mathrm{Cs},{ }^{137} \mathrm{Cs},{ }^{110 \mathrm{~m}} \mathrm{Ag},{ }^{60} \mathrm{Co}\right.$, and $\left.{ }^{55} \mathrm{Fe}\right),{ }^{14} \mathrm{C}$, and ${ }^{3} \mathrm{H}$. And their orders of magnitude are $10^{9}, 10^{7}, 10^{3}, 10^{6}$, and $10^{8}$ Bq per MW of HTR-PM, respectively.

\section{Dose Calculation and Optimization Routine}

5.1. Dose Calculation. For the primary shielding, the $1 \mathrm{D}$ ANISN [19] and 2D DOT codes [20] are used to calculate the distribution of the neutron flux and $\gamma$ rays.

For various secondary shieldings, $\gamma$ radiation sources can be a primary concern, which are calculated using KORIGEN code [21], a Karlsruhe version of the Oak Ridge Lab's ORIGEN [22]. Because of the moving feature of the fuel elements, there can be multiple radiation sources in a single radiation protection task. To deal with this spatiotemporal complexity, an in-house software tool that calculates the dynamic dose field for multiple radiation sources is developed, which uses multidimensional point kernel and buildup factor methods to estimate gamma transport in room scale. A 3D visualization module has been developed to better model complex structures and radiation source movement $[16,23]$.

5.2. Optimization Routine. Although the movement of fuel elements makes the radiation protection complex, it also brings the freedom of changing the spatiotemporal distribution of radiation sources through careful transport path design. To take advantage of this freedom, an iterative optimization routine (Figure 2) is formed and applied to all radioactivity-related systems in HTR-PM. During the iteration, the dose reduction scheme and the system design are jointly optimized to achieve the ALARA goal with consideration of the maintenance procedures, dose rates, and work durations. The iteration continues until both the dose constraint in Figure 1 and the ALARA principle is met. Typical examples using the routine in Figure 2 for optimization of radiation protection will be described in the next section.

\section{Radiation Optimization in System Design}

6.1. Reactor Cavity. The activation of equipment inside the reactor cavity is a key concern of the radiation protection

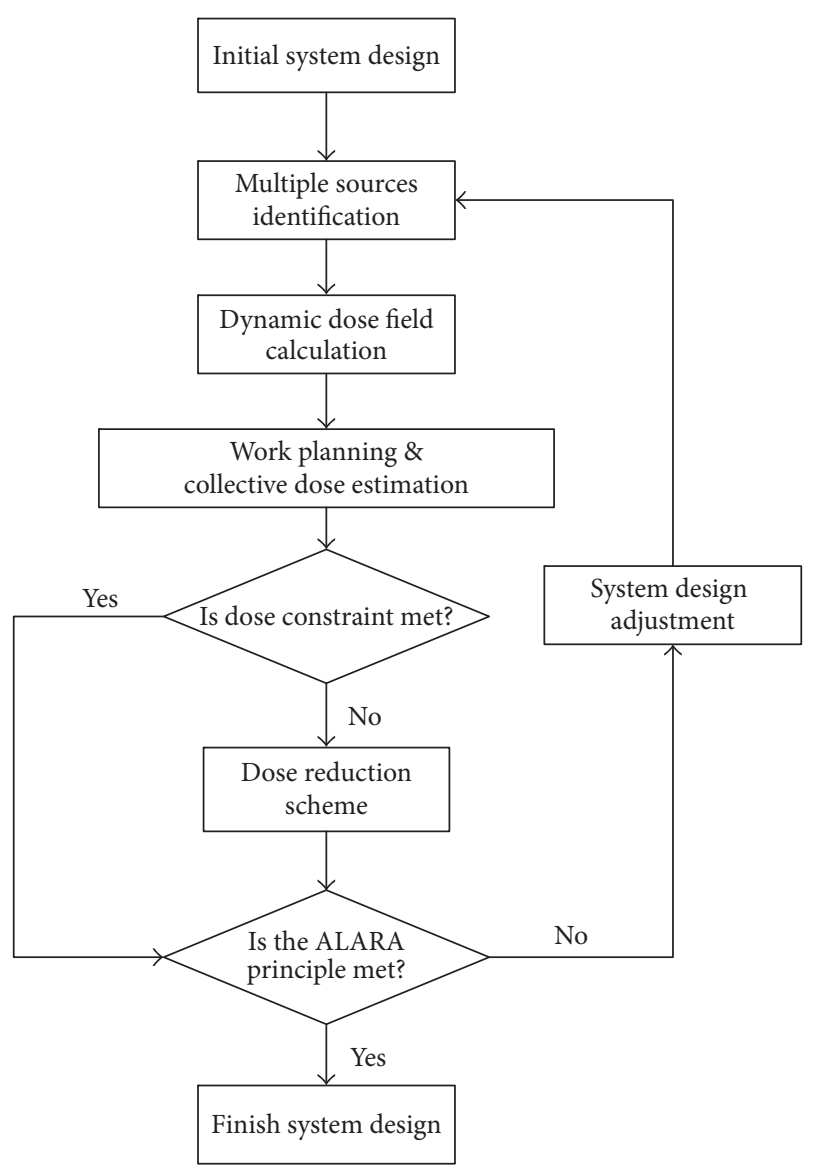

FIGURE 2: Flowchart of the radiation protection optimization routine for HTR-PM.

for the maintenance work after the reactor is shut down. Therefore, the cobalt impurities are required to be less than $0.02 \%$ in the design of HTR-PM, while the sample analysis result reveals that the actual percentage of the cobalt impurities is even lower.

Because staff receive radiation from different equipment, a joint consideration of work flow and the radiation contribution from all related equipment is necessary for optimizing the radiation protection. Figure 3(a) shows the dose reduction design for the maintenance work on top of $\mathrm{RPV}$, which receives the radiation from the steel plates on the cavity cap and the cavity wall, the drivers of both control rods, and absorber balls, and the steel maintenance platform and the dose limit are $1 \mathrm{mSv} / \mathrm{h}$ for this maintenance. Before optimization, both the drivers of control rods and the steel plate on the cap contribute high dose rates to the position of interest (Figure 3(b)). During the optimization process, several dose reduction methods have been compared. The first dose reduction method, in which the boron-containing polyethylene plate is installed for reducing neutron flux, works for all the radiation sources in Figure 3(a). However, the dose rate of the drivers of control rods still exceeds the dose limit (Figure 3(c)), and the installation requires additional support structures which may not be available. The second method is the cobalt impurity control. But it is so 


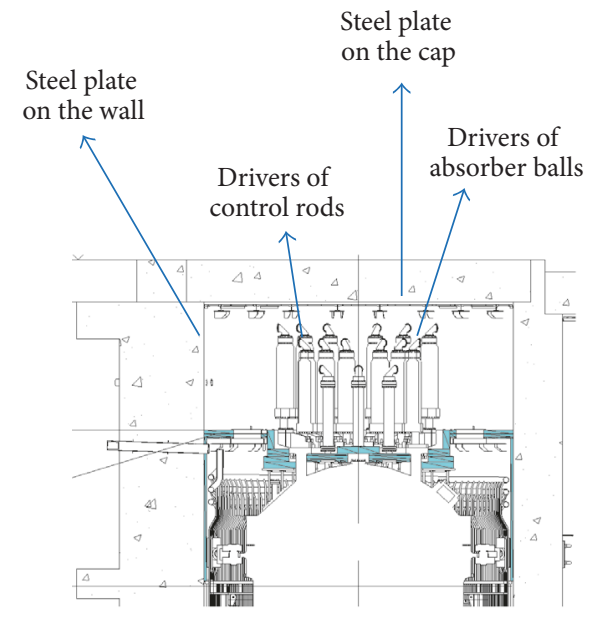

(a)

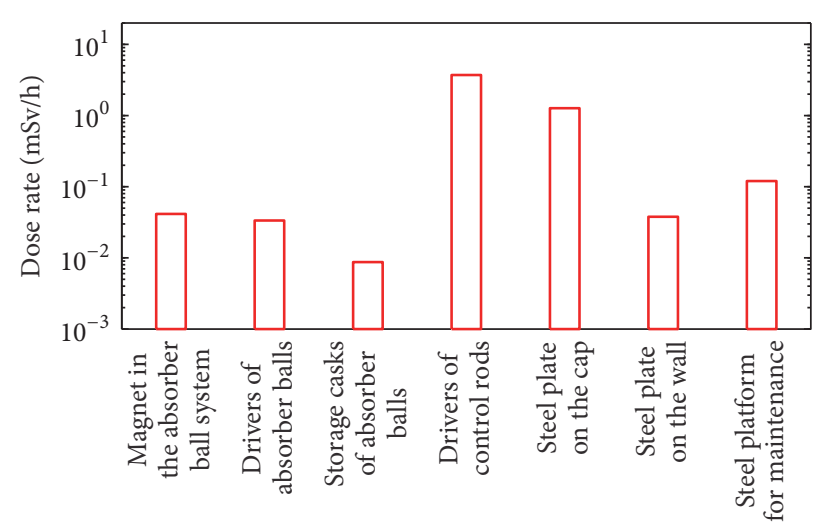

(b)

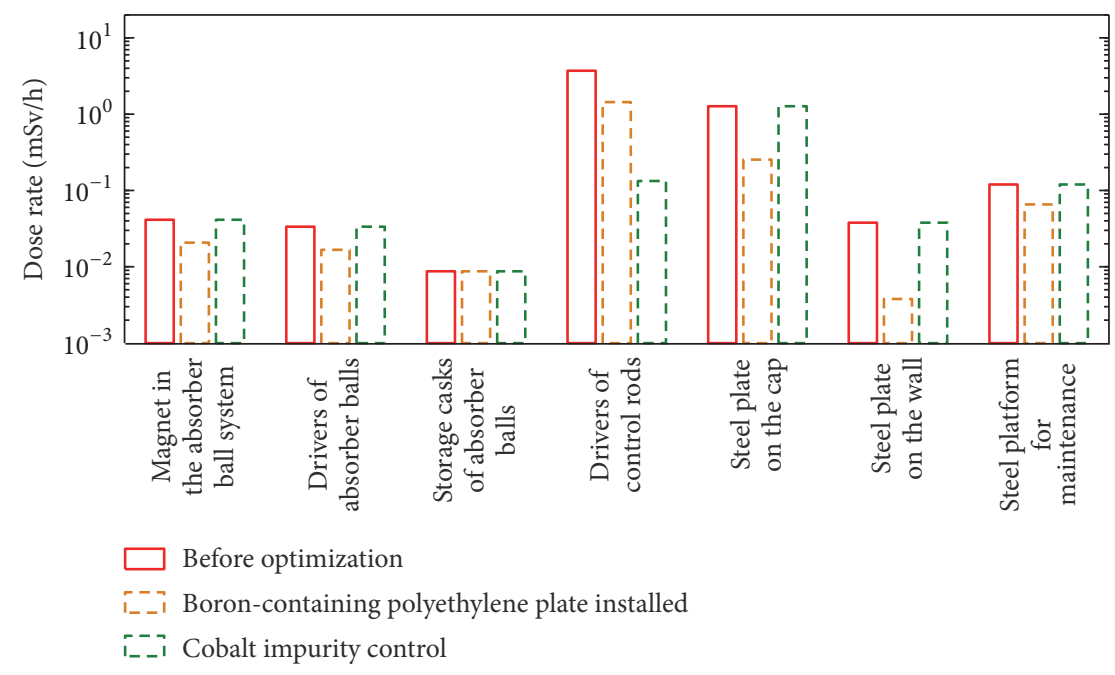

(c)

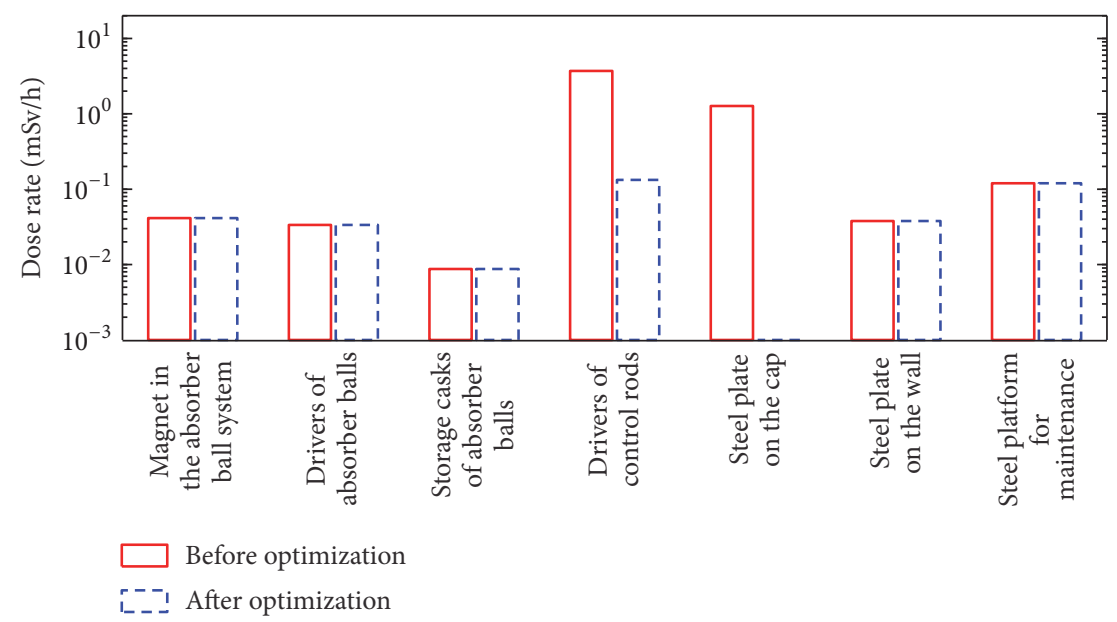

(d)

FIgURE 3: (a) The dose reduction design for the maintenance work on top of RPV; (b) dose rates of different equipment for the maintenance work on top of RPV; (c) dose rates before optimization and after boron-containing polyethylene plate installed or cobalt impurity control; (d) dose rates before and after optimization. 


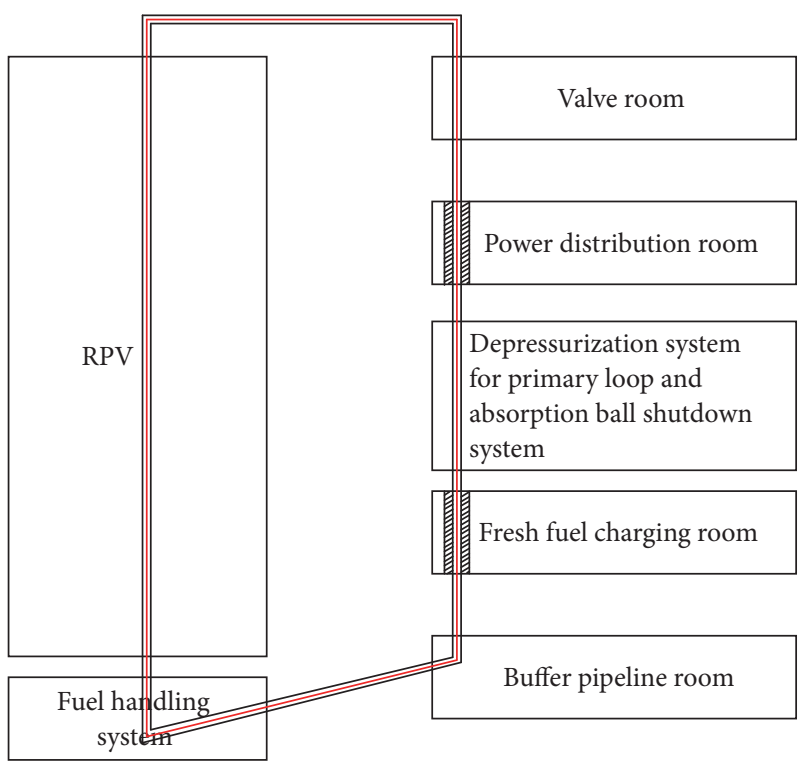

FIGURE 4: Simplified sketch of the fuel transportation path and the related room layout. The red line indicates the primary fuel transportation path and the shaded block indicates the concrete shielding wall.

expensive that it is only affordable to implement the cobalt control on the drivers of control rods. Therefore, the cobalt control does not reduce the radiation from steel plate on the cap (Figure 3(c)), of which the contributed dose rate exceeds the dose limit. In order to round this dilemma, the work flow of the maintenance is modified so that the cap together with the steel plate will be removed first before the maintenance work starts. This removes a critical radiation source in the maintenance and makes it only necessary to implement the cobalt control on the drivers of control rods, which saves a lot of expenses. As the final result, the collective dose rate is reduced to $0.49 \mathrm{mSv} / \mathrm{h}$, with affordable cost (Figure 3(d)).

6.2. Fuel Handling System. Two features of the fuel handling system are the moving fuels and its large pipe loop for fuel transferring, which passes several rooms as shown in Figure 4. For those rooms that require the access of staff, a thick concrete shielding wall is used to lower the radiation to an acceptable level (shaded block in Figure 4). In the related radiation protection design, the dynamic dose rate evaluation is performed to avoid inappropriate overestimation in traditional static evaluation, so that the radiation protection is optimized toward a good balance between costs and benefits.

Figure 5 shows one typical example, in which the position of interest receives the radiation from three different fuel elements that are moving downwards in three nearby pipes, respectively (Figure 5(a)). The dynamic evaluation reveals that the instant dose rate varies considerably as the fuels move to different heights (Figure 5(b)). Given the dose limit $(0.0075 \mathrm{mSv} / \mathrm{h})$, the daily averaged dose rates are evaluated with both dynamic calculation and static calculation (which uses the peak values of the instant dose rates in Figure 5(b)). As shown in Figure 5(c), the static evaluation is so conservative that it suggests a $30 \%$ growth of the density of the concrete wall to meet the dose limit. This density growth will significantly increase the cost, weight, and requirement for supporting structures. In comparison, the dynamic method provides a more realistic dose rate estimate which proves that the dose rate can meet the dose limit with current concrete shielding and avoid the unnecessary cost.

6.3. Spent Fuel Storage System. The spent fuel storage system transfers the spent fuel elements and graphite spheres for reactor starting from the different storage casks and stores these casks in silos underground. The spent fuel elements are highly radioactive, so the spent fuel storage casks are equipped with very thick shielding.

But the graphite spheres are only mildly radioactive and their number is much less than that of the spent fuel elements, which makes it inefficient to use the same shielding as the spent fuel cask. Therefore, both shielding and increasing distance strategies are utilized, in order to reduce the shielding thickness and the related cost (Figure 6(a)). Figure 6(b) shows the calculated dose rate contour for different combination of the steel shielding thickness and the distance prohibited to access, together with the dose limit plane. The dose rate contour under the dose limit plane corresponds to the combinations that meet the requirement. Based on these combinations, the layout of equipment around the graphite sphere casks is adjusted accordingly, in order to achieve an optimal combination that reduces both the prohibited distance and shielding thickness. Figure 6(c) compares the combination before and after optimization. The thickness of the shielding is reduced from $20 \mathrm{~cm}$ to $15 \mathrm{~cm}$. The prohibited distance mildly increases from $30 \mathrm{~cm}$ to $130 \mathrm{~cm}$. However, this increase has no substantial influences on the maintenance of different equipment, because no maintenance work is required within this distance.

When loading the spent fuel elements to the storage cask, both the cask and the moving fuels are radiation sources that can potentially threat staff. In this case, a joint design with consideration of multiple sources and shielding is necessary to achieve the optimal combination. Figure 7(a) shows an optimization example for the spent fuel storage system, which consists of two moving sources, one static source and two shielding structures. The aim of this calculation is to ensure that the dose rate under the concrete floor is within the requirement of the radiation zoning. Using the routine in Figure 2, different combinations of these two shielding structures are calculated as the candidates for optimization. The dose contour under the plane of the dose limit in Figure 7(b) shows all the available combinations that meet the given dose limit $(0.03 \mathrm{mSv} / \mathrm{h})$. With consideration of other aspects, such as maintenance requirements and support structures, a final optimized result is selected from the available choices shown in Figure 7(b). Compared to traditional separate design before optimization, the combination after optimization reduces the thickness of concrete and 


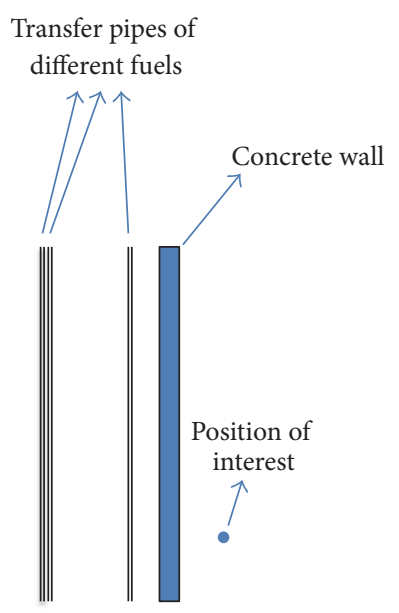

(a)

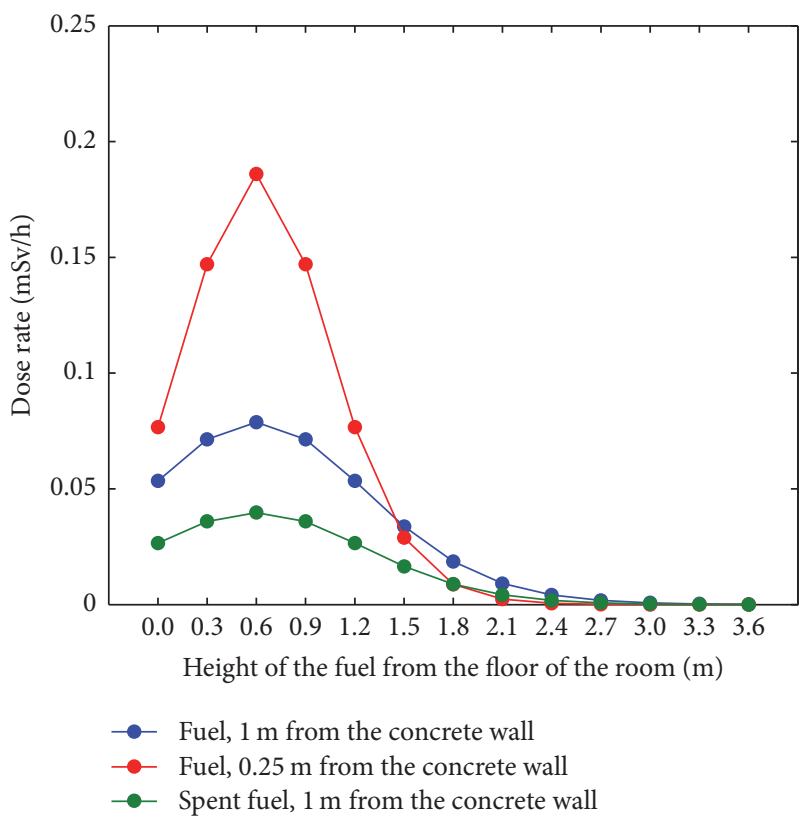

(b)

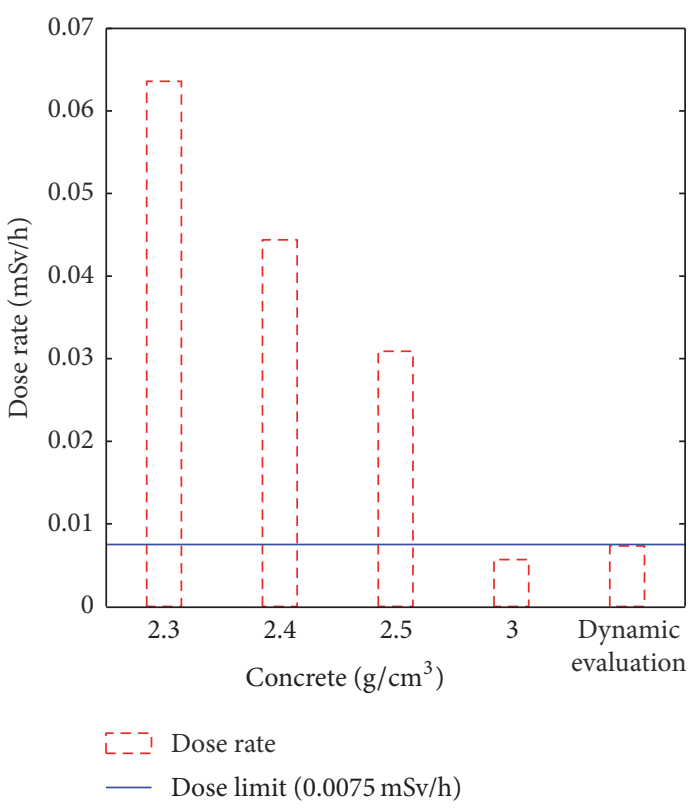

(c)

Figure 5: (a) An example of fuels moving and irradiating a position of interest; (b) the dynamic evaluation of dose rates; (c) dose rates with different densities of the concrete and dynamic evaluation.

the shielding for the pipe by $62.5 \%$ and $45.0 \%$, respectively (Figure 7(c)).

\subsection{Other Strategies for Radiation Optimization}

6.4.1. Layout Aspect. Compartments of different radiation zonings are physically separated by shielding or concrete walls. The access to these rooms is provided by independent corridors, in which the maximum dose rate is lower than $0.0075 \mathrm{mSv} / \mathrm{h}$. Nonradioactive equipment is physically separated from radioactive equipment, so as to avoid radiation damage and unnecessary occupational exposure in nonradioactive work. And the ventilation system ensures that the air only flows from the nonradioactive area to the radioactive area. Radioactive equipment is usually concentrated in a single room, in order to make the best of the shielding walls.

6.4.2. Radiation Source Reduction. The fresh fuel elements of HTR-PM are vacuumized to remove $\mathrm{N}-14$ before being charged into the reactor core, so that the corresponding activation product C-14 is reduced. The helium purification system of HTR-PM removes the radionuclides and other contaminations in the primary coolant. The metal and iodine in the coolant are filtered by the dust filter. H-3 and C-14 are oxidized into tritium water and ${ }^{14} \mathrm{CO}_{2}$, respectively, which are retained by the molecular sieve. Gaseous contaminations are absorbed by the activated carbon. 


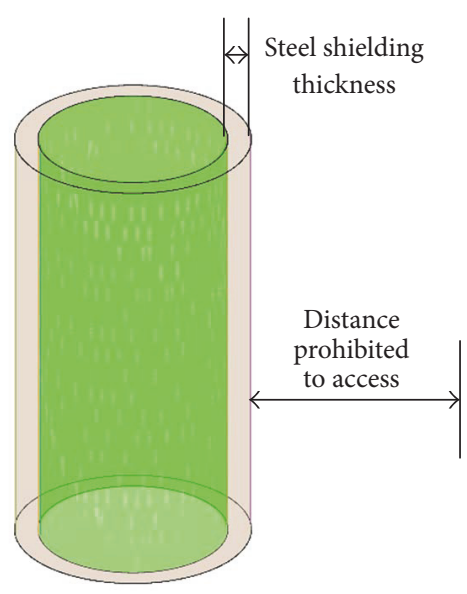

(a)

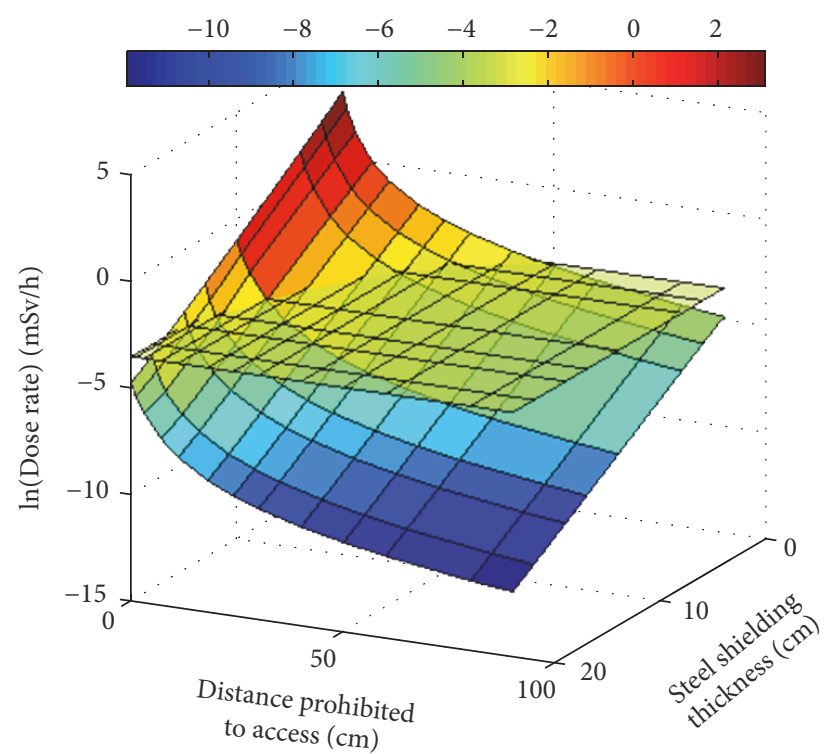

(b)

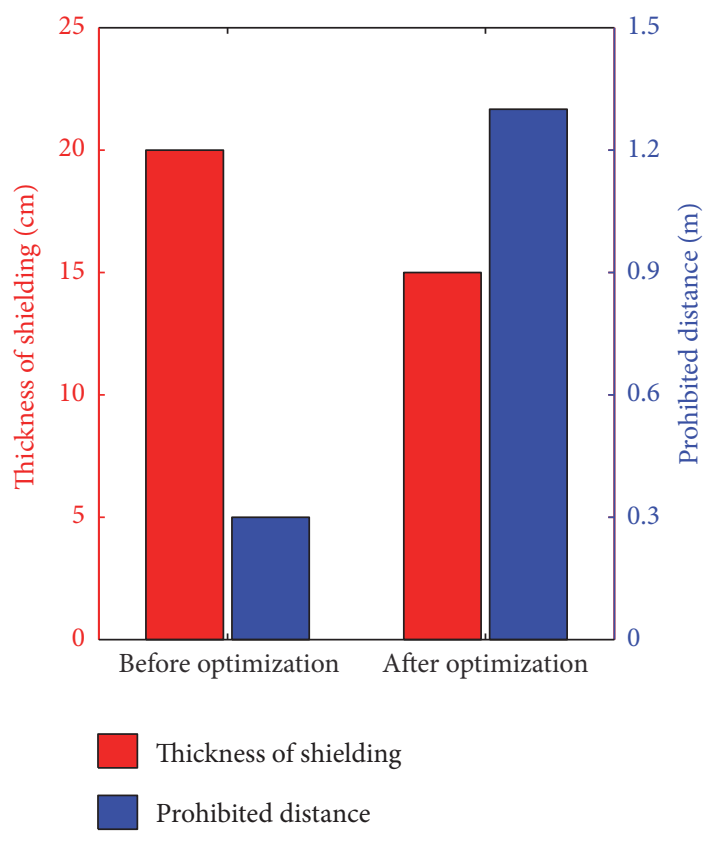

(c)

FiguRE 6: (a) Sketch of the graphite sphere cask; (b) the dose limit plane $(0.03 \mathrm{mSv} / \mathrm{h})$ and the dose rate contour of the graphite sphere storage cask with respect to distance and the thickness of shielding; (c) the dose rate and prohibited distance before and after optimization.

6.4.3. Radiation Tolerance. The tolerance of radiation damage is another important concern with respect to the reliability of components. By calculating the cumulative dose, the radiation damage is evaluated with different shielding designs and spatial arrangements. The design that best matches the IAEA-provided thresholds for radiation damage to materials [24] and ALARA principle is chosen.

\section{Annual Collective Dose Estimate Optimization}

With the optimization of radiation protection, a refined annual collective dose is estimated and compared with the previous rough estimate before optimization for each system.
7.1. Fuel Handling System. The primary maintenance work of the fuel handling system takes place in several rooms, most of which is done in the fuel handling system room and the buffer pipeline room.

Before optimization, no maintenance details were considered for the fuel handling system room. Consequently, there were only very rough estimates, for which the total annual work duration was 140 man-hours and the average dose rate was $0.03 \mathrm{mSv} / \mathrm{h}$. During optimization, the maintenance work is broken down into very specific tasks such as the repair of the fuel discharging equipment, the replacement of its motor, and the ultrasonic measurement of the thickness of pipe elbows. And the intervals between two maintenances have also been established for these tasks, which are two years 


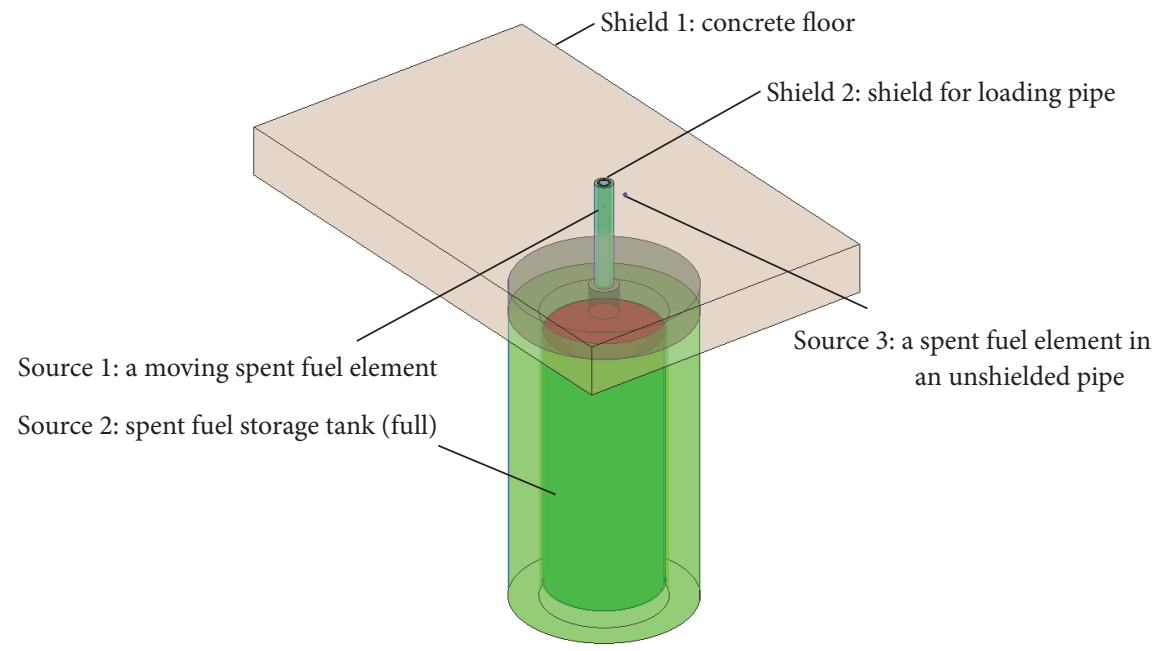

(a)

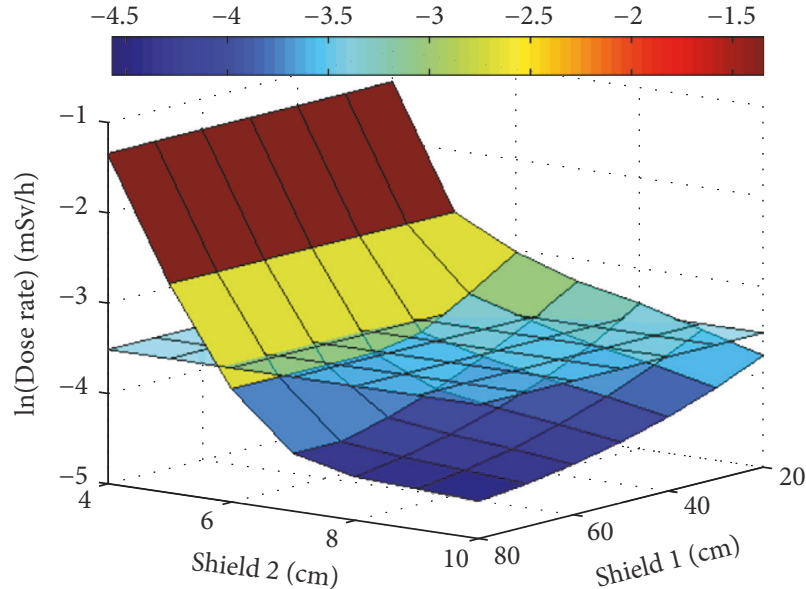

(b)

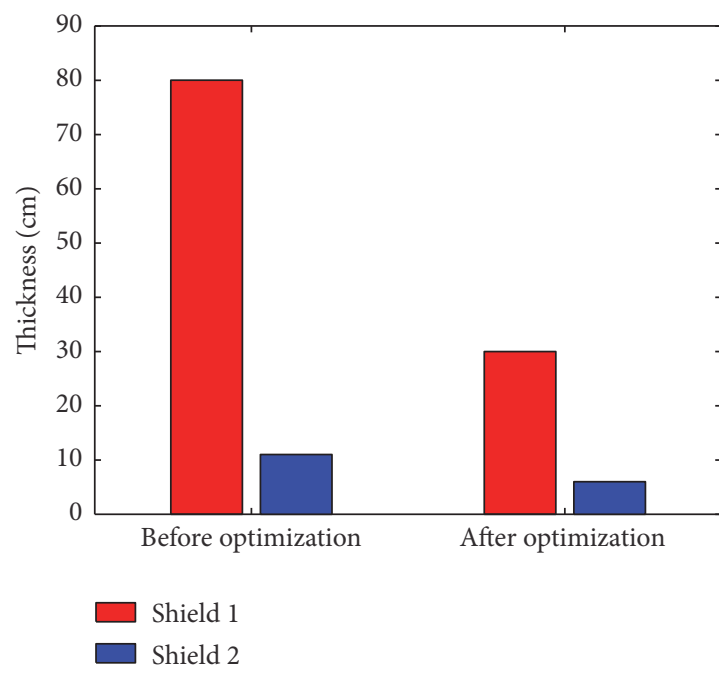

(c)

FIGURE 7: The optimization of the concrete floor and the shielding for the loading pipe. (a) The radiation computation model generated by the in-house tool; (b) dose rate contour and dose limit (the transparent plane); (c) the comparison between the designs before and after optimization.

for most tasks and four years for others. The establishment of these maintenance cycles provides a more realistic estimate of the work duration (total 29 man-hours), which is much less than the previous estimate. The dose rates are also replaced with spatially varying calculation results, for which the maximum exceeds $1 \mathrm{mSv} / \mathrm{h}$ and the minimum is $0.0046 \mathrm{mSv} / \mathrm{h}$ (Figure 8(a), work positions 1 and 6).

For the buffer pipeline room, the annual work duration and the average dose rate were estimated to be 70 manhours and $0.03 \mathrm{mSv} / \mathrm{h}$, respectively, before optimization, in the absence of detailed maintenance information. During optimization, the analysis of work contents reveals that the maintenance intervals of the equipment in this room can be quite long, which are two, four, six, or even ten years. This significantly reduces the annual average work durations, for tasks like the inspection of magnetic buffer components, the ultrasonic measurement of the thickness of pipe elbows, the repair of the fuel charging equipment, the replacement of the server system, and so on. As a result, the optimized total annual work duration is 28 man-hours. The dose rates at most maintenance work positions are generally below $0.001 \mathrm{mSv} / \mathrm{h}$ (Figure 8(b)), because most radioactive fuel elements in this room are removed in advance and the only remaining radiation source (i.e., the container of graphite dust which is far away from work positions) is well-shielded. However, for the ultrasonic thickness measurement and the inspection of magnetic buffer components, the work positions are difficult to identify and the dose rates are unable to be calculated consequently. Thus, the dose rates of these two tasks are set to the maximal dose rate $(0.03 \mathrm{mSv} / \mathrm{h})$ allowed by the radiation 


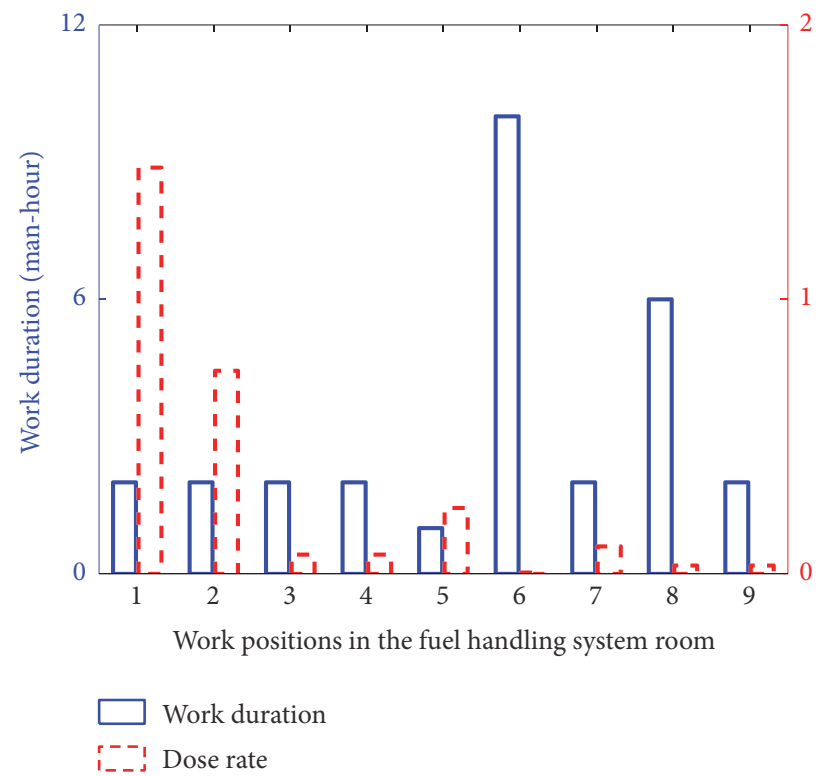

(a)

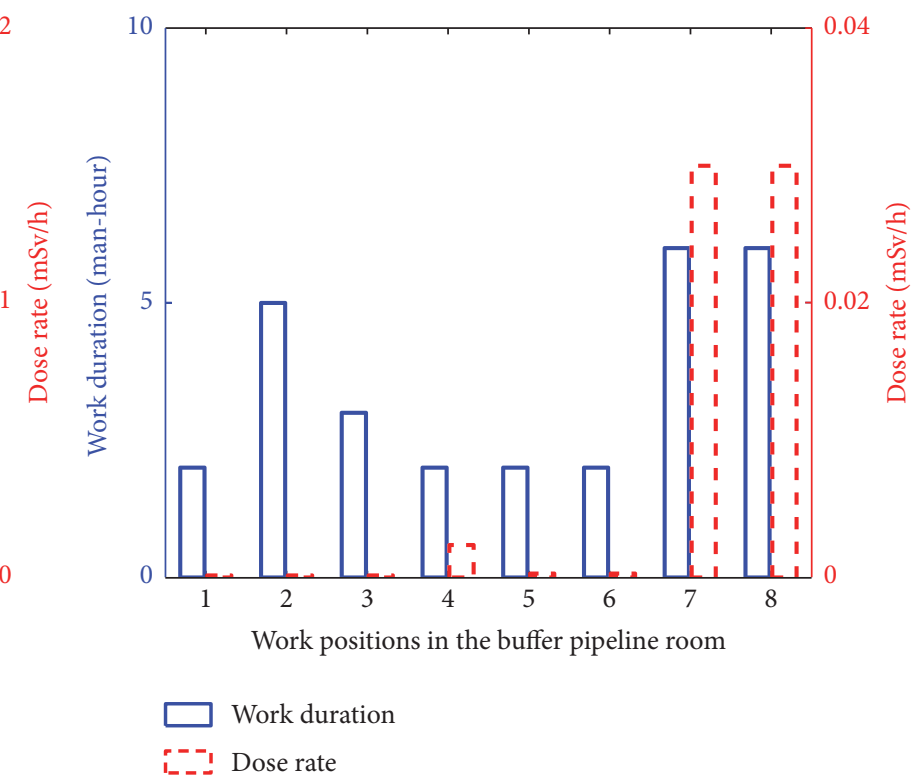

(b)

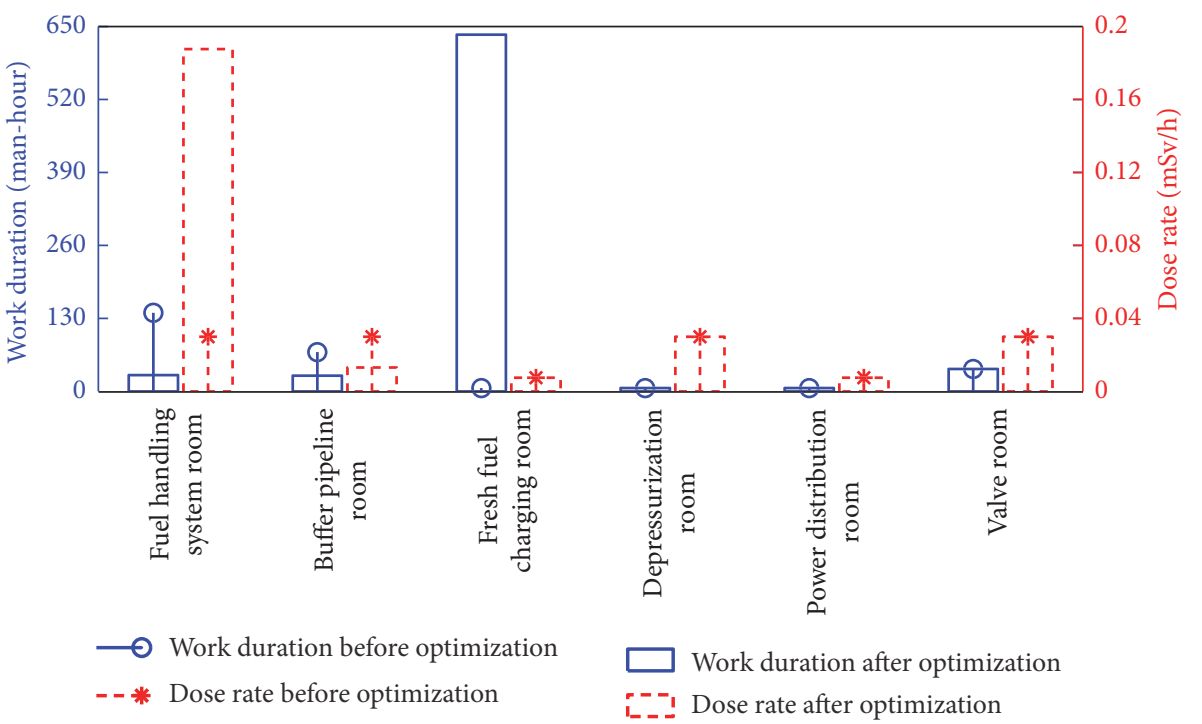

(c)

FIGURE 8: Dose rates and work durations in (a) the fuel handling system room; (b) the buffer pipeline room; and (c) different rooms of the fuel handling system.

zone for this room (Figure 8(b), work positions 7 and 8), which is a conservative estimate. In a real case, the dose rates for these two tasks may be lower than the estimate.

Figure 8(c) summarizes the dose rates and work durations in different rooms of the fuel handling system before and after optimization, respectively. The work duration in the fuel handling system room is reduced after the refined estimation, while the corresponding average dose rate is increased after optimization. For the buffer pipeline room, both the work duration and the average dose rate are reduced after optimization. For the other four rooms, the ultrasonic thickness measurements every two years are the major radioactive tasks, for which the dose rates are $0.03 \mathrm{mSv} / \mathrm{h}$ or $0.0075 \mathrm{mSv} / \mathrm{h}$ according to the upper limits of the corresponding radiation zones. Although this estimation is a little conservative, it can handle the uncertainties in the identification of work positions and corresponding dose rates well.

7.2. Control Rod System, Air Circulator, and Hoist. Before optimization, the annual maintenance work duration and dose rate related to the control rod system were 4 man-hours and $3 \mathrm{mSv} / \mathrm{h}$, respectively. According to the experience in HTR-10, the maintenance work mainly involves the disassembly and replacement of the electrical penetrations, the drivers, and different equipment of the control rod system, which are implemented every 10 years. Based on this maintenance cycle, 
TABLE 3: The annual work durations and dose rates of RPV, SG, and helium circulator.

\begin{tabular}{lcccc}
\hline Work position & $\begin{array}{c}\text { Work duration } \\
\text { (man-hours) }\end{array}$ & $\begin{array}{c}\text { Dose rate } \\
\text { (mSv/h) }\end{array}$ & $\begin{array}{c}\text { Collective dose } \\
\text { (man-Sv/a) }\end{array}$ \\
\hline \multirow{3}{*}{ RPV } & 1 & 15 & 3.50 & 199.05 \\
& 2 & 15 & 3.63 & \\
\hline \multirow{3}{*}{ SG } & 3 & 30 & 1.78 & 62.82 \\
& 4 & 10 & 3.87 & \\
& 1 & 50 & 0.91 & 54.02 \\
Helium circulator & 2 & 50 & $3.89 \times 10^{-4}$ & 0.12 \\
& 3 & 50 & 0.95 & 1.75 \\
\hline
\end{tabular}

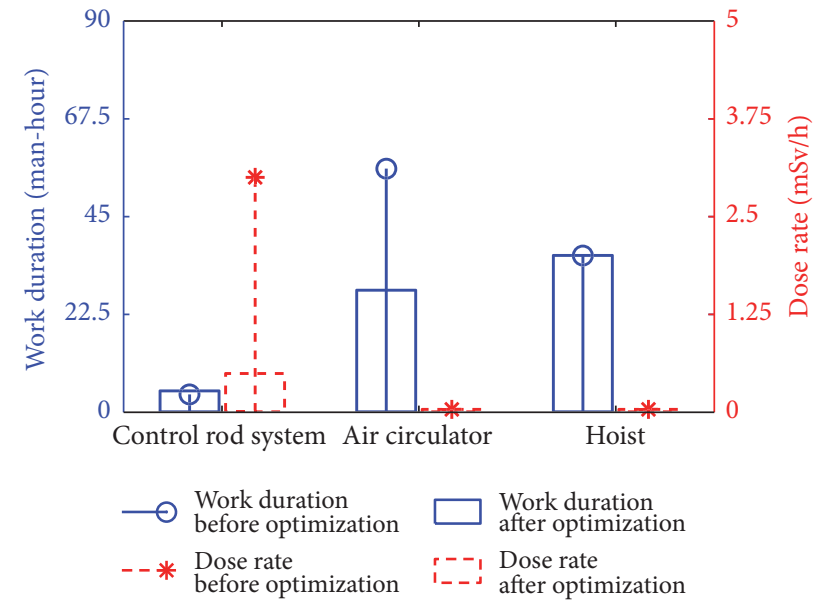

FIGURE 9: Dose rates and work durations of the control rod system, air circulator, and hoist.

the annually average work duration for the control rod system is estimated to be 4.8 man-hours (Figure 9). And the dose rate at the work position is $0.49 \mathrm{mSv} / \mathrm{h}$, after the work flow optimization in Figure 3.

As for the air circulator and hoist, their maintenances do not involve radioactivity. But in order to be appropriately conservative, the dose rates are set to the upper limit $(0.03 \mathrm{mSv} / \mathrm{h})$ of the reactor maintenance hall, where the maintenance work takes place. Before optimization, the annual work duration of the air circulator was conservatively estimated as 56 man-hours with no consideration of the detailed work contents. During optimization, the maintenance work of the air circulator is specified as the inspection and cleaning which are conducted every two years. Based on the maintenance schedule, the final annual work duration is 28 man-hours (Figure 9).

7.3. RPV, Steam Generator ( $S G$ ), and Helium Circulator. The maintenance work of these three components contributes the majority of the annual collective dose estimate, of which the dose rates and annual work durations are summarized in Table 3. For RPV and SG, the annual work durations and dose rates are estimated according to the experiences of similar maintenance work on other advanced reactors in China. For the helium circulator, the experiences of the maintenance work on HTR-10 [25] are referred to estimate the annual work duration and dose rate.

For RPV, four representative positions are chosen for the collective dose estimation, including the top head and bottom head of RPV (work positions 1 and 4) and the positions above and below the hot gas duct (work positions 2 and 3). The dose rates at these positions are all above $1 \mathrm{mSv} / \mathrm{h}$, which are considerably high. Therefore, the robotic and remote flaw detection equipment is widely used to reduce the work duration and occupational dose. The optimized work durations at these four positions are $15,15,30$, and 10 man-hours. The corresponding collective dose is estimated to be 199.05 man-Sv/a. However, this estimate does not take the effect of personal radiation protection into consideration. Therefore, it can be viewed as the upper limit of the collective dose.

For SG, its dose rates show variations between chosen representative positions, from lower than $0.001 \mathrm{mSv} / \mathrm{h}$ to almost $1 \mathrm{mSv} / \mathrm{h}$ (Table 3 ). The helium leakage detection and pressure test every two years are identified as the primary maintenance work and the total estimated work duration is 200 man-hours. Because of the uncertainties of work positions, the total estimated work duration is divided equally into four parts for the four representative positions. The resultant collective dose estimate is lower than $1 / 3$ of that of RPV.

With respect to the helium circulator, the maintenance work involves the inspection and repair of the internal components every five years and the replacement of vulnerable parts of the helium circulator and its electrical penetrations every ten years. The representative dose rates near the helium circulator are lower than RPV but higher than SG (Table 3). The corresponding work durations are estimated based on recent experiences on the helium circulator of HTR10 [25]. Because the interval between two maintenances of 


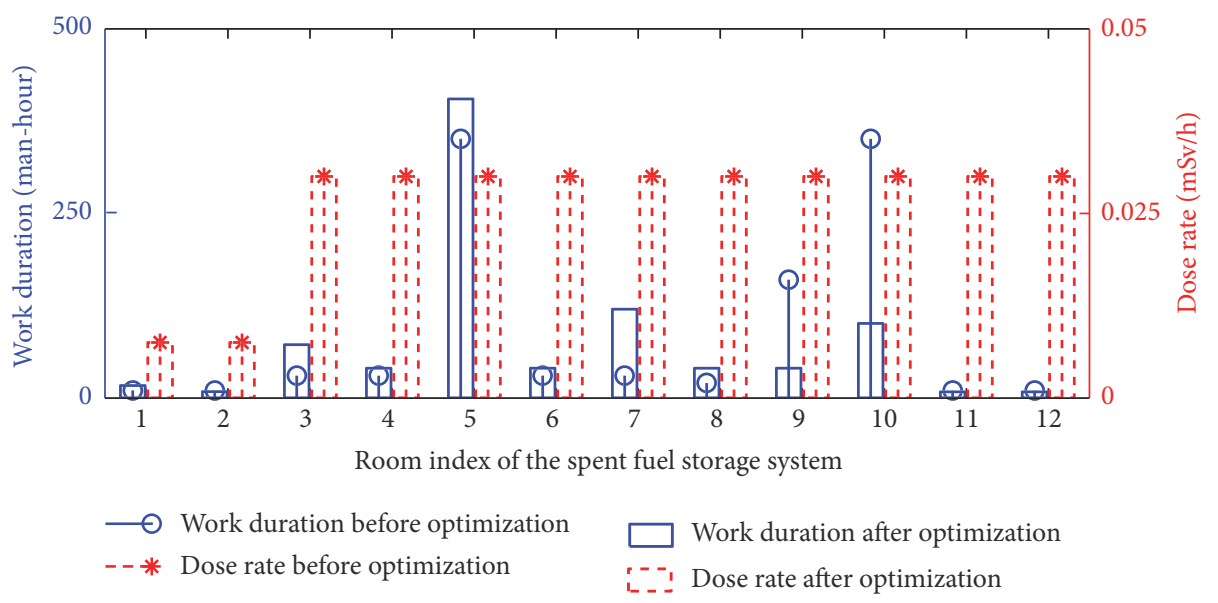

FIGURE 10: Dose rates and work durations of rooms of the spent fuel storage system.

the helium circulator is much longer than RPV and SG, the corresponding annual work duration and the collective dose are lower than those of RPV and SG.

7.4. Spent Fuel Storage System. The maintenance work of the spent fuel storage system involves 12 rooms. In the maintenance stage, the fuels in these rooms are removed so that the dose rates are quite low. However, the maintenance work can take place at any corner of any room, which makes it difficult to choose representative work positions. In order to deal with the uncertainties, the upper limits of radiation zones for these rooms are used as the representative dose rates (Figure 10). Meanwhile, the investigation of work contents shows that the major tasks in the ventilation equipment room mainly involve the inspection of the bearing lubrication every two years and the replacement of the bearings and electrical components every ten years (Figure 10, room 9). These long maintenance cycles reduce the annual work duration from 160 man-hours to 40 man-hours. For the electrical equipment room, the robotic and remote detection techniques are intensively used to replace the manual inspection on site, which greatly reduces the work duration in the radioactive environment by $71.3 \%$ (Figure 10, room 10). For rooms 5 and 7 , the work durations slightly increase. After optimization, the annual average collective dose for the whole spent fuel storage system decreases by $4.41 \mathrm{man}-\mathrm{mSv} / \mathrm{a}$, compared to that before optimization.

7.5. Helium Purification System. For the helium purification system, the maintenance work details were not specified before optimization. Therefore, the dose rate was set to the upper limit of the radiation zone which is $3 \mathrm{mSv} / \mathrm{h}$ and the annual work duration was 36 man-hours for conservative considerations. During optimization, the major work that involves radioactivity is identified as the maintenance of the compressors, valves, and instruments every two years. For them, the upper limit of the radiation zone is used as the representative dose rate and the work duration is estimated to be 2.5 man-hours. Another task that might need radiation protection is the replacement of the dust filter every twenty years. For this task, the refined dose rate estimate is
$0.54 \mathrm{mSv} / \mathrm{h}$ and the annual work duration is estimated to be 1 man-hour after optimization.

7.6. Liquid/Solid Waste Disposal System and Ventilation System. These three systems only involve very limited radioactivity, for which the work durations remain much the same as those before optimization. But the dose rate calculation is further refined for better estimation of collective dose rates.

For the liquid waste disposal system, the dose rates of the maintenance work were all set to the upper limits of the corresponding radiation zones before optimization. To get optimized estimates, the dose rate calculation is improved with the developed software. For example, the dose rate at the work position near the evaporator is estimated to be $0.0035 \mathrm{mSv} / \mathrm{h}$ after optimization (Figure 11, position 1 of the liquid waste disposal system), when the evaporator is fully loaded with liquid waste. If the radioactive liquid in the evaporator is removed before maintenance, the dose rate can be even lower than the above estimate. Dose rates near the liquid waste storage cask and evaporator equipment are estimated to be $0.0055 \mathrm{mSv} / \mathrm{h}$ and $0.0056 \mathrm{mSv} / \mathrm{h}$, respectively, after optimization (Figure 11, positions 2 and 3 of the liquid waste disposal system). The work durations are estimated to be equal at all these three positions, which are the same as those before optimization.

For the solid waste disposal system, the dose rates at primary work positions are 0.021 and $0.025 \mathrm{mSv} / \mathrm{h}$, respectively, after refined dose estimation, which are more realistic than previous estimates before optimization.

As for the ventilation system, the radiation zone is changed from the green zone in the previous design to the yellow zone in the current design. Therefore, the dose rate estimate which is the upper limit of the radiation zone increases from $0.0075 \mathrm{mSv} / \mathrm{h}$ to $0.03 \mathrm{mSv} / \mathrm{h}$. Besides, the work duration estimate is slightly increased to 8 man-hours with the consideration of the additional preparation stages.

7.7. Absorber Ball System. The absorber ball system was not analyzed in the previous estimate. According to the experiences on HTR-10, the maintenance work of the absorber ball 


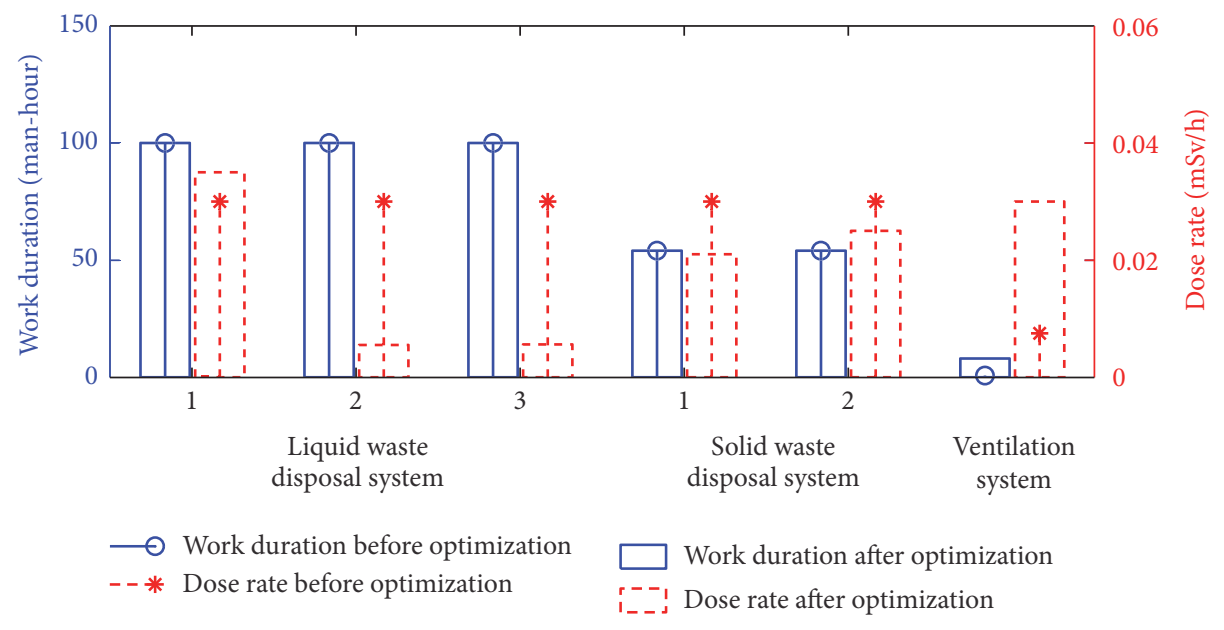

FIGURE 11: Dose rates and work durations of the liquid/solid waste disposal system and ventilation system.

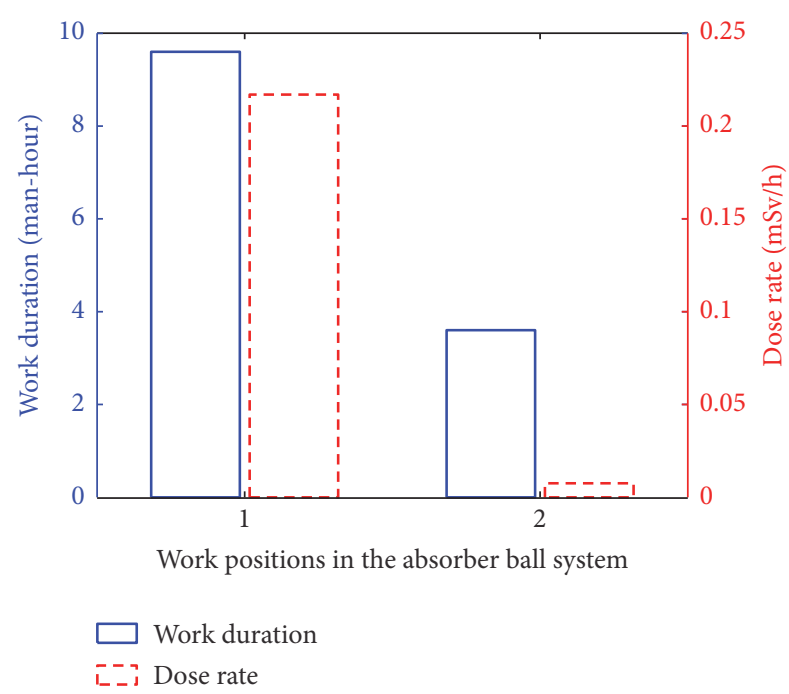

Figure 12: Dose rates and work durations of the absorber ball system.

system also involves radioactivity. The primary radioactive maintenance work of this system is the replacement of its drivers and other components. For the replacement of the drivers, the dose rate is $0.217 \mathrm{mSv} / \mathrm{h}$ and the work duration is 9.6 man-hours (Figure 12, work position 1). For the maintenance work of other components, the dose rate is $0.0075 \mathrm{mSv} / \mathrm{h}$ and the work duration is estimated to be 3.6 man-hours (Figure 12, work position 2).

7.8. Total Annual Collective Dose. The optimized annual collective dose estimates for primary systems are compared with the estimates before optimization in Figure 13. The total annual collective dose after optimization is $0.445 \mathrm{man}-\mathrm{Sv} / \mathrm{a}$, which is reduced by $9.18 \%$ from the previous $0.490 \mathrm{man}-\mathrm{Sv} / \mathrm{a}$ before optimization. The annual collective dose of the helium purification system shows the most significant decrease after optimization, due to the refined dose rates and more realistic work duration estimates than those before optimization. For the control rod system, its annual collective dose is reduced by $9.65 \mathrm{man}-\mathrm{mSv} / \mathrm{a}(80.4 \%)$, as a result of the optimized work flow and radiation protection practices. There are also decreases of the annual collective dose for the air circulator, spent fuel storage system, and liquid/solid waste disposal system. It is noticeable that the annual collective doses may not always decrease for every system, because the optimization aims at the ALARA principle, instead of a sole decrease of the dose. For example, the annual collective dose of the fuel handling system increases by $54.5 \%$ after optimization, because of a more detailed investigation on the work flow. The collective dose of the ventilation system also increases, because the radiation zoning is adjusted for its room. And the absorber ball system which is neglected in the previous estimate is also added to the analysis. This demonstrates that the presented framework not only optimizes the quantities such as dose rate and work duration but also completes the radiation protection design.

\section{Conclusion}

The optimization of radiation protection in the HTR-PM's design stage is reviewed and presented as a systematic framework in this study. A routine that jointly optimizes system design and radiation protection is proposed and presented with typical calculations of optimization tasks for the radioactivity-related systems, including the control rod and absorber ball system in the reactor cavity, fuel handling system, and spent fuel storage system. The optimization using this routine quantitatively achieves the reduction of either the dose rate or the shielding or both for these systems by about $23.3 \% \sim 90.6 \%$. Based on the refined dose rate estimation and work flow, the annual collective doses of different systems are optimized and compared against the previous estimates. The comparison reveals that the annual collective dose of HTR$\mathrm{PM}$ is reduced from $0.490 \mathrm{man}-\mathrm{Sv} / \mathrm{a}$ before optimization to $0.445 \mathrm{man}-\mathrm{Sv} / \mathrm{a}$ after optimization, which complies with the requirements of the Chinese regulatory guide. 


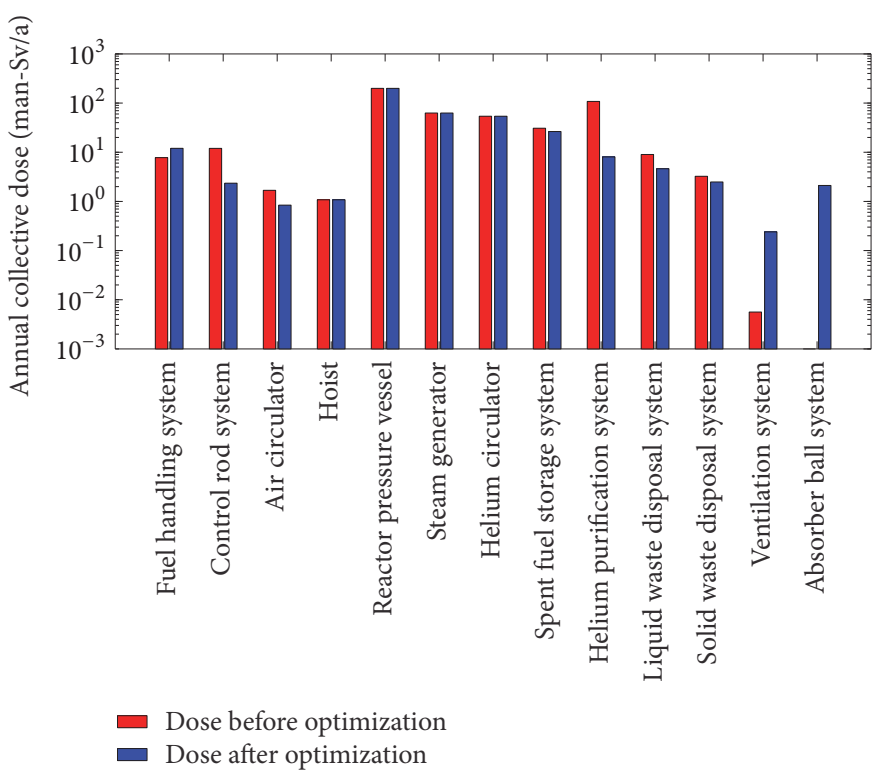

FIGURE 13: Collective dose of HTR-PM before and after optimization.

\section{Conflicts of Interest}

The authors declare that they have no conflicts of interest.

\section{Acknowledgments}

The authors greatly acknowledge the financial support from the National Natural Science Foundations of China (Grant no. 11475100), the Education Ministry Foundation of China (Grant no. 20151080400), and the Foundation of Key Laboratory of Advanced Reactor Engineering and Safety of the Ministry of Education (Grant no. ARES201410).

\section{References}

[1] ICRP, "Recommendations of the ICRP," Annals of the ICRP, vol. 1, no. 3, 1977.

[2] ICRP, "A compilation of the major concepts and quantities in use by ICRP," Annals of the ICRP, vol. 14, no. 4, 1985.

[3] ICRP, "1990 Recommendations of the international commission on radiological protection," Annals of the ICRP, vol. 21, no. 1-3, 1991.

[4] ICRP, "The optimisation of radiological protection: broadening the process," Annals of the ICRP, vol. 36, no. 3, pp. 69-87, 2006.

[5] ICRP, "The 2007 recommendations of the international commission on radiological protection," Annals of the ICRP, vol. 37, no. 2-4, 2007.

[6] J. Baum, Occupational Exposures and Practices in Nuclear Power Plants, Brookhaven National Lab., New York, NY, USA.

[7] A. Gauvenet, "Radiation protection practices and experience in French operating reactors," Nuclear Technology, vol. 72, no. 3, pp. 246-253, 1986.

[8] J. Hildebrand, "Experience in the optimization of radiation protection practices during the cleanup of Three Mile Island Unit 2," Optimization of Radiation Protection, 1986.
[9] G. Vivian and K. Donnelly, A Canadian Nuclear Power Producer's Approach to The Optimization of Design for Radiation Protection, IAEA, 1986.

[10] R. Wilson, G. A. Vivian, W. J. Chase et al., "Occupational dose reduction Experience in Ontario Hydro nuclear power stations," Nuclear Technology, vol. 72, no. 3, pp. 231-245, 1986.

[11] M.-S. Yim and H. Ocken, "Radiation dose management in nuclear power plants," Progress in Nuclear Energy, vol. 39, no. 1, pp. 31-51, 2001.

[12] E. Baumann and I. R. Terry, "The EPR: a clear step forward in dose reduction and radiation protection," Nuclear Engineering and Design, vol. 236, no. 14, pp. 1720-1727, 2006.

[13] B. Doehnert, "Design of the Ap 1000 power reactor," in Proceedings of the International Conference on Nuclear Energy for New Europe Portorož, September, 2006.

[14] R. Bäumer, H. Barnert, E. Baust et al., AVR-Experimental HighTemperature Reactor, 21 Years of Successful Operation for a Future Energy Technology, VDI-Verlag GmbH, Düsseldorf, Germany, 1990.

[15] H. Wahsweiler and I. Kalinowski, "Experience in Optimization of Operational Radiation Protection in The THTR 300," in SVA further education course: Optimization of the radiation protection from the design to the decommissioning of nuclear installations, 1987.

[16] S. Fang, H. Li, J. Cao, W. Li, F. Xie, and J. Tong, " $\gamma$ dose rate estimation and operation management suggestions for decommissioning the reactor pressure vessel of htr-pm," in Proceedings of the 15th International Conference on Environmental Remediation and Radioactive Waste Management, p. V002T03A005, Brussels, Belgium.

[17] N. N. S. Administration, Radiation Protection Design for Nuclear Power Plants, National Nuclear Safety Administration, 1990.

[18] I. A. E. Agency, Radiation Protection and Safety of Radiation Sources, International Basic Safety Standards, 2014.

[19] W. W. Engle Jr, A users manual for anisn: a one dimensional discrete ordinates transport code with anisotropic scattering, Oak Ridge Gaseous Diffusion Plant, Tennessee,Tenn, USA, 1967. 
[20] F. Mynatt, "DOT III two-dimensional discrete ordinates transport code," Tech. Rep., Oak Ridge National Laboratory, Tennessee, Tenn, SA, 1973.

[21] U. Fischer and H. W. Wiese, Verbesserte konsistente Berechnung des nuklearen Inventars abgebrannter DWR-Brennstoffe auf der Basis von Zell-Abbrand-Verfahren mit KORIGEN, Ber./KFK, 1983.

[22] M. Bell, "ORIGEN-The Oak Ridge Isotope Generation and Depletion Code," ORNL, p. 4628, 1973.

[23] S. Sun, S. Fang, and H. Li, "Radiation Shielding Design of High Temperature Reactor Pebble-Bed Module (HTR-PM)," in Proceedings of the 24th International Conference on Nuclear Engineering, American Society of Mechanical Engineers, 2016.

[24] H. Ullmaier and W. Schilling, Radiation Damage in Metallic Reactor Materials, 1980.

[25] C. Guo, L. Wei, H. Li, J. Cao, and S. Fang, "Radiation protection practices during the helium circulator maintenance of the 10 mw high temperature gas-cooled reactor-test module (HTR10)," Science and Technology of Nuclear Installations, vol. 2016, Article ID 5967831, 13 pages, 2016. 


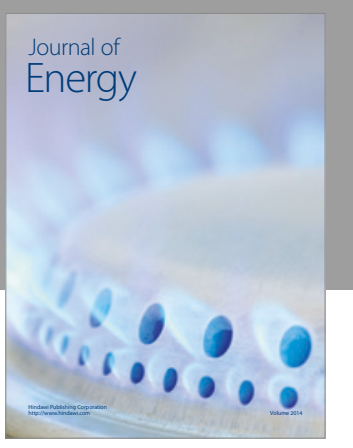

Journal of

Industrial Engineering
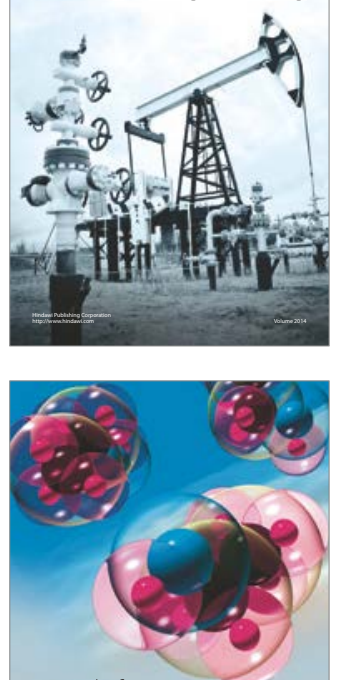

Fuels
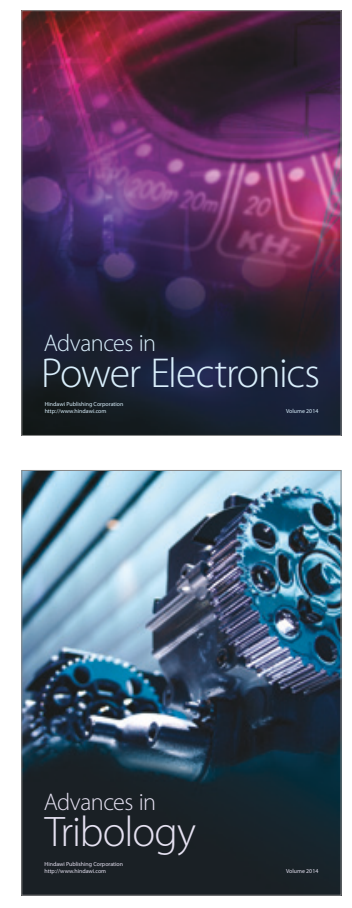
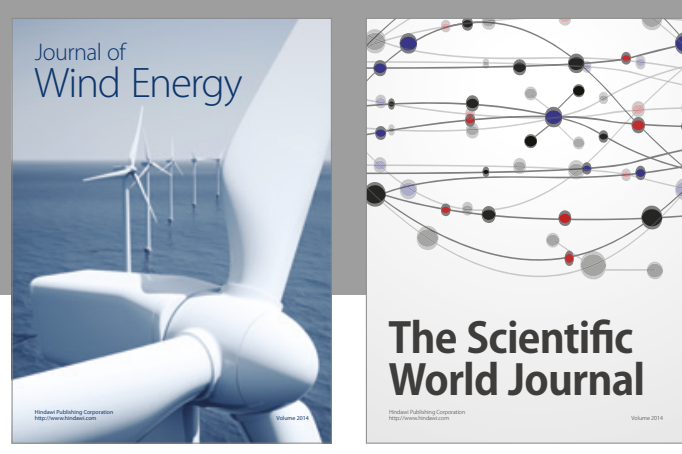

The Scientific World Journal
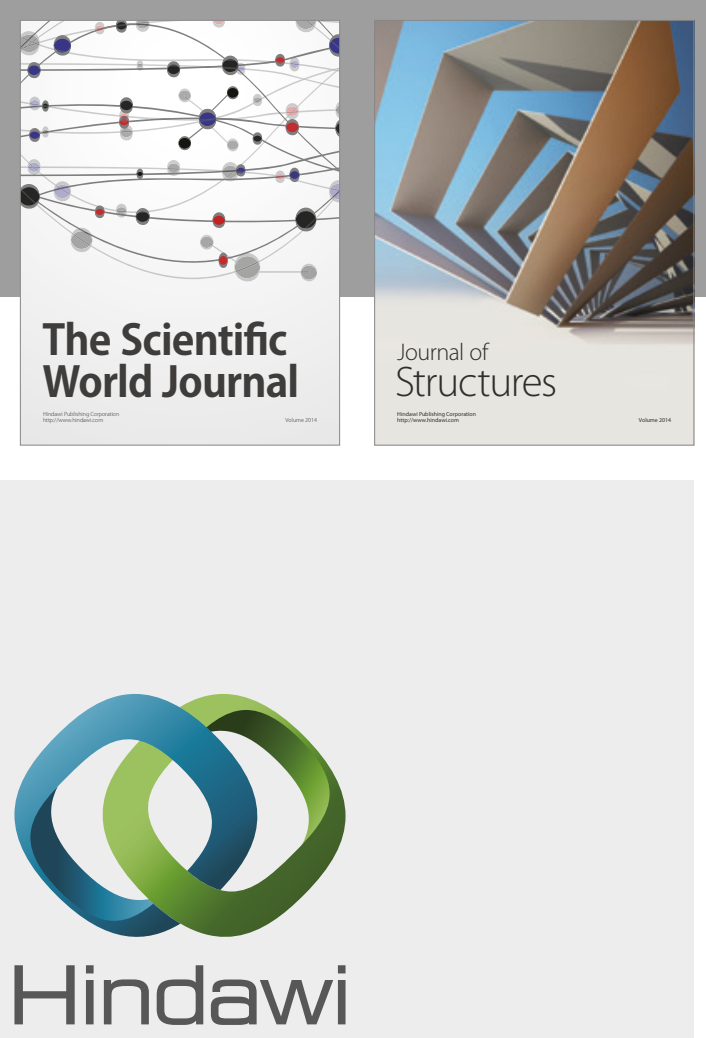

Submit your manuscripts at

https://www.hindawi.com
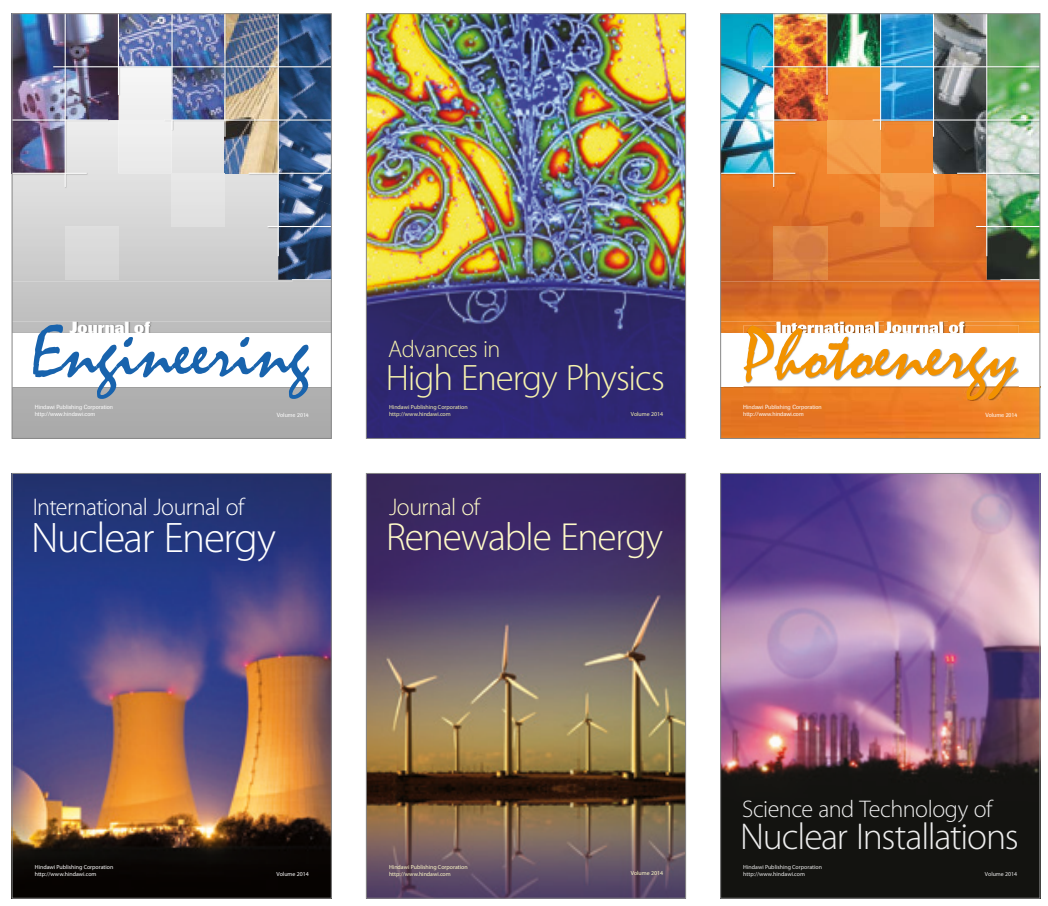

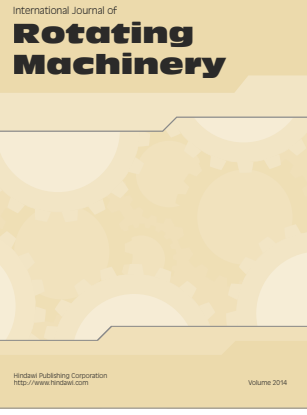

Journal of

Petroleum Engineering

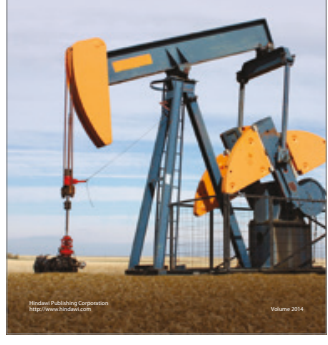

Journal of
Solar Energy
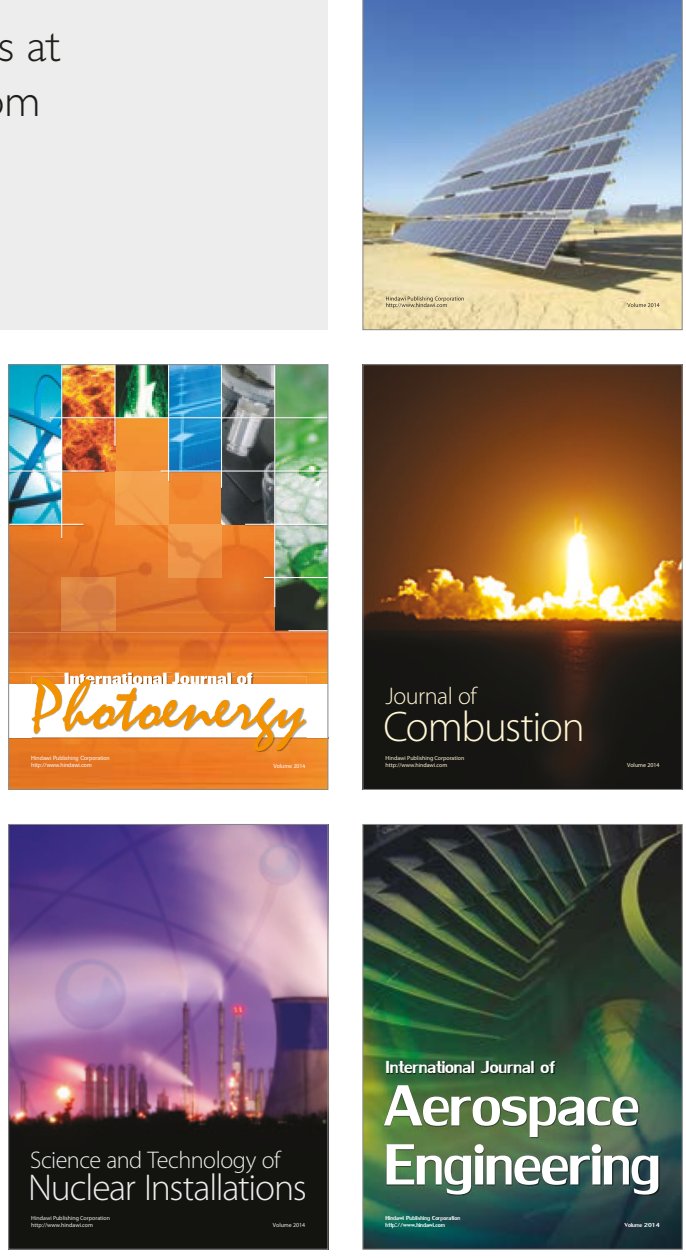